Article

\title{
The Effect of Introducing Parking Policies on Managing Mobility to Beaches in Touristic Coastal Towns
}

\author{
Gonzalo Antolín, Borja Alonso* $*$, Rubén Cordera ${ }^{\circledR}$ and Luigi dell'Olio \\ Department of Transportation, University of Cantabria, Av. de Los Castros 44, 39005 Santander, Spain \\ * Correspondence: alonsobo@unican.es
}

Received: 13 May 2019; Accepted: 25 June 2019; Published: 27 June 2019

check for updates

\begin{abstract}
This article presents a behavioural analysis of tourists visiting a leisure area in the north of Spain to evaluate their reaction when faced with a series of tariffs and alternative transport modes to estimate potential income for reinvestment in sustainable mobility policies. The active involvement of the different groups affected by the changes has led to a series of policies able to generate income for financing a new urban transport service, park and ride installations and their associated vehicles. These changes resulted in a noteworthy improvement in the quality of life of the local residents and an improved, less intense tourist experience.
\end{abstract}

Keywords: parking choice; stated preference; mobility management; parking policy

\section{Introduction}

The problems associated with increased traffic levels and parking saturation can affect most settlements, especially those located in tourist areas that attract high volumes of visitors concentrated at specific limited time periods, in other words, those destinations specialising in seasonal or festival related tourism, where the traffic volumes vary greatly depending on the time of year. Although they generate income and job creation in the area, if these periods are not managed correctly, they can also cause serious problems for the local residents and a series of negative externalities in terms of mobility and pollution $[1,2]$.

These externalities can have repercussions on the number of tourists [3]. Phillips and House [4] studied the perception of three different strata of beach tourism (surfing, eco-tourism and family) from the point of view of the destination choice criteria. Variables such as massification and cleanliness (in terms of both water and the environment) were found to be the most valued in the survey and, interestingly, both of these aspects usually have an inverse relationship with visitor numbers. However, the efficient management of mobility, and how to make it easier and more comfortable for tourists has been one of the main aspects that favoured the increase of travellers [5,6]. Gutiérrez and Miravet [7] studied how tourists in coastal areas behaved in relation with the existing local public transport services, finding that in large settlements, the tourists parked their own vehicles in areas further away from the beach and travelled by bus to and from the holiday areas. However, the same research found that this behaviour did not occur in smaller settlements. The fact that areas with better public transport services are more likely to receive tourists to coastal areas has also been confirmed in the research by Mandeno [8].

This complex relationship, along with the environmental perception of the tourist, has been explained by Petrosillo et al. [9]. On the one hand, the leisure or recreational behaviour is indirectly affected by environmental quality and, on the other hand, the tourist has the power to directly affect this quality through their own individual behaviour [10]. Also, the development of sustainable mobility strategies and plans contributed to the increase of travellers in the area [11]. 
Phillips and Jones [12] highlighted the importance of the sustainable control of coastal zones. According to Bramwell and Lane [13], the interrelationships between tourism and the environment are of vital importance and it has been widely recognised that sustainable tourism is essential both for the tourist industry itself and the natural environment. Snousy et al. [14] presented research highlighting the importance of economic development for certain zones while maintaining the high quality of tourism being supplied in the area.

Research specifically targeting parking has found that restrictive policies involving tariffs have traditionally been introduced as have entrance tolls to try and reduce the impact of traffic and congestion in very popular areas. Examples can be found in the research made by Nurul Habib et al. [15] or by Chaniotakis and Pel [16]. Varied experiences have been reported in the literature about managing mobility in tourist zones, such as the construction of private pay car parks [17].

Any measure introduced to manage a specific problem has been usually based on a stick and carrot approach, in other words, restrictive measures (generally tariffs) complemented by measures aimed at favouring the use of more sustainable alternative modes of transport, accompanied by some form of bonus or incentive. An analysis has been performed on the impact of measures, such as road closures [18] or on the provision of public transport services [19].

Steiner and Bristow [18] and Ragnerus et al. [20] addressed some very interesting cases of how traffic management has impacted national parks, analysing the resistance of users to such measures [21]. The authors addressed the conflict between the different actors involved in the process, the lack of information provided to the user and their perceptions, particularly those visitors who were arriving in the area for the first time.

However, Ragnerus et al. [20] and Holding and Kreutner [22] found that the politicians (and therefore, their decisions) have been strongly influenced by the opinions of the residents and the pressures brought by the hotel and tourist related industries. Many of these industries are run by non-residents in the area and their interests conflict with those of the residents themselves, as they consider any restrictions will have a negative effect on their incomes [23]. This perception has also been examined from opposing points of view [24].

There are also differences in perception between travellers for reasons of leisure to the coast and residents of the area where the beach area is located. In the case of the United States, it was determined that residents were willing to pay $\$ 2.46$ to improve access. For their part, travellers for leisure purposes were willing to pay $\$ 6.33$ [25].

Conflicting interests from opposing factions have tried to influence political decision making which sometimes goes against expert technical criteria. Different points of view from the tourism lobby and residents resulted in a common final problem suffered by all the agents involved, that is, the difficult mobility caused by massification and traffic congestion.

As a way of managing these mobility issues, a stated preference survey was carried out in a touristic beach in the north of Spain for the evaluation of user behaviour with different policies focused on dissuading the use of private cars. Thus, Section 2 introduces the study case. Section 3 discusses the stated preferences (SP) survey used in the present case study and its design process is explained. Section 4 describes the discrete choice models that were obtained, and the most relevant results derived from the models. Section 5 describes the simulations developed for different policies that could be introduced by the local authorities and, finally, the conclusions drawn from this research are presented in Section 6.

\section{Description of the Case Study}

The case studied in this article is a coastal town called Arnuero (Cantabria) located on the Northern Spanish coast. This location has two separates recreational areas which are the subject of the present research (Figure 1). The study area 1 is called Isla beach (Figure 2a). It is a small beach which some facilities such a camping, a small hotel, two hostels and bed and breakfast, and a large car park near the beach. The beach only can be accessed by a rolling road (two kilometres length) from a small village 
called Isla. The study area 2 (Figure $2 b$ ) is called Quejo. It is the main town of the municipality and concentrates most of the accommodation (small hotels, hostels, bed and breakfast and two camping areas). It has two larger beaches next to the town centre. The access to all beaches is free for all users. The municipality (formed by the main town and five small villages) has a small regular population of only 2100 people. However, during the summer months the population increases to 4300 additional temporary residents. Most of them are placed in all the villages of the municipality, use their cars to go to the beaches located at the two study areas. Furthermore, 1500 daily vehicles access the beach during the summer coming from other municipalities, most of them being temporary residents during the summer period. This influx of people and vehicles has caused serious road congestion problems throughout the holiday period (the queues of traffic waiting to enter the town can stretch up to $5 \mathrm{~km}$ ) and an abuse of public space for parking vehicles.

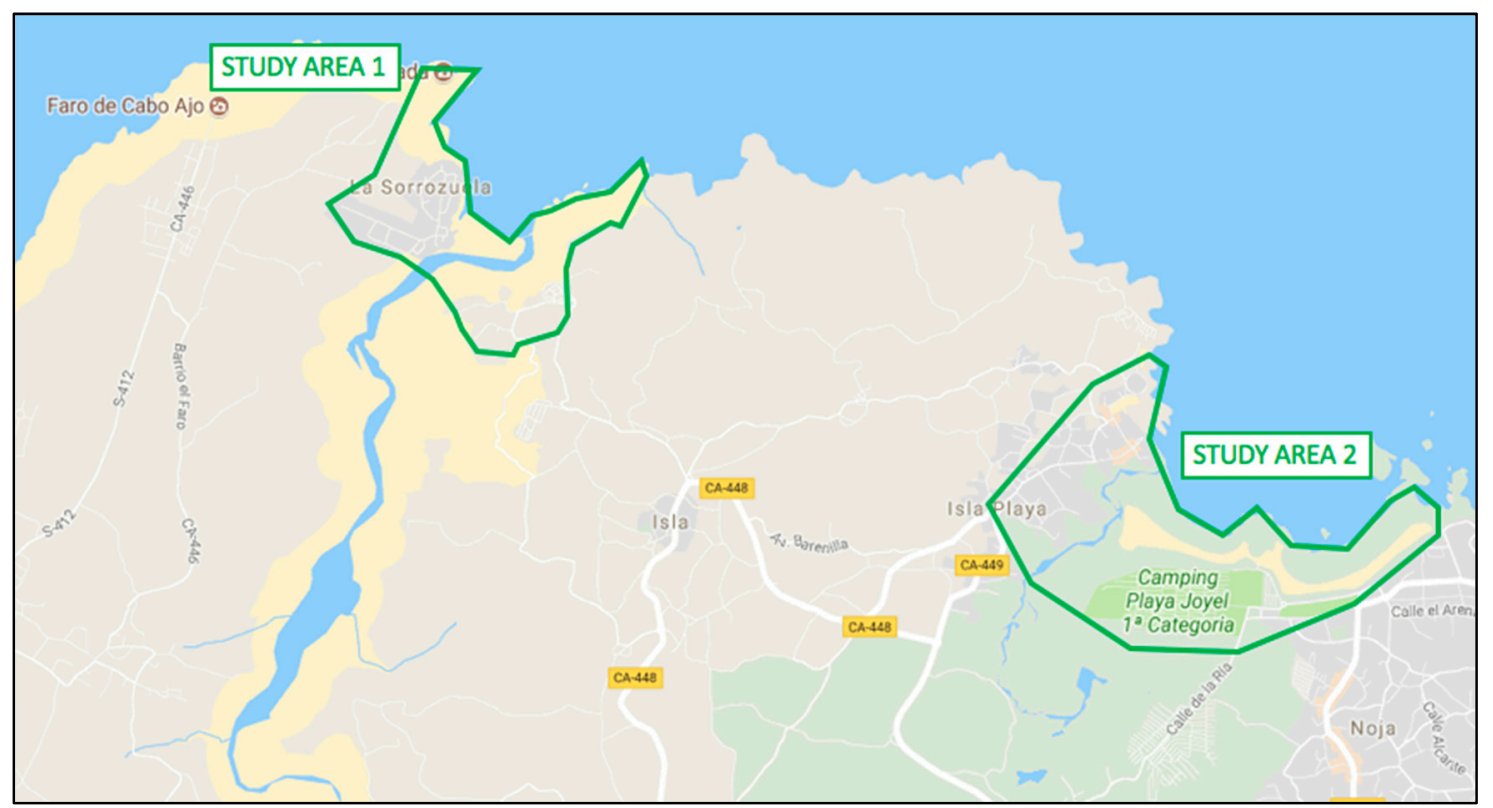

Figure 1. The two zones included in the study area.

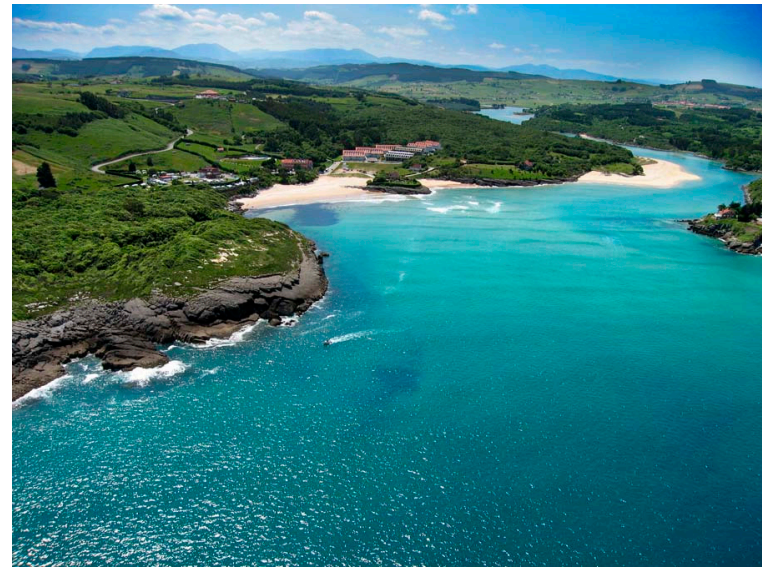

(a)

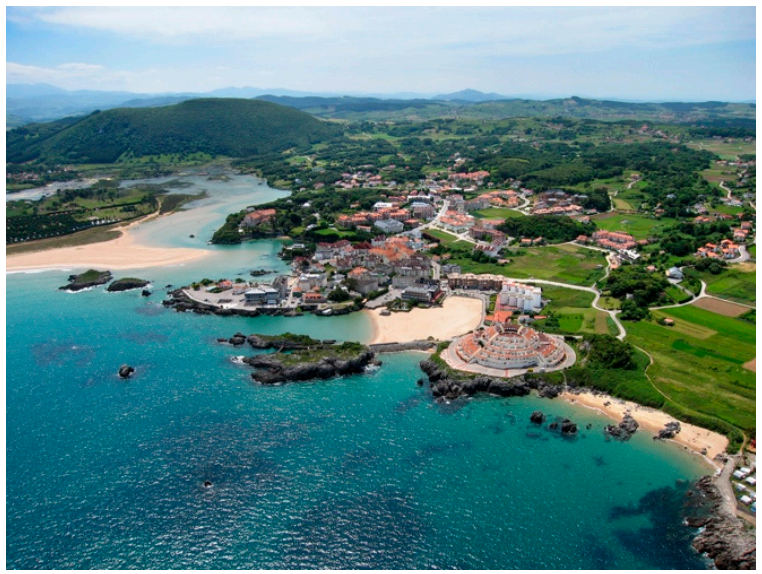

(b)

Figure 2. A detailed view of the study area 1 (a) and study area 2 (b). Source: CIT-Centro de Iniciativas Turísticas de Isla.

The distance between the two recreational zones belonging to the borough increases the need to travel and the provision of sufficient facilities in both zones to individually absorb the demand during the most popular periods. 
All this led the local authorities to create more than 2000 new temporary parking spaces on urban land (by using empty terrains available) and around the beaches (less than $10 \mathrm{~min}$ far walking from the Quejo beaches), together with three large park and ride (P and R) car parks on available land along the main access road to the town where the only connection was a cycle lane. The $P$ and $R$ facilities are located 1.5-2.5 km far from the Quejo beaches and 3-4 km far from the Isla beach. All these measures follow the recommendations made by the Sustainability Mobility Plan of the municipality.

Faced with the possibility that the action they were taking was going to provoke a massive influx of tourists to the area, the local authority decided to study the demand resulting from the introduction of complementary policies to restrict private car use, encourage using the $\mathrm{P}$ and $\mathrm{R}$ car parks and pay for their maintenance and management.

\section{Stated Preference Experiment}

A stated preferences survey was initially designed to find the potential demand resulting from each of the possible policies to be introduced and to obtain the most representative variables when choosing which mode of transport to use and, where relevant, which type of parking policy to choose. The survey data was then applied to develop discrete choice models, (mixed logit (ML) models), supported by simulations of the potential scenarios and systems to define the distribution of users among the different choice alternatives available in the survey.

The final stated preference survey consisted of five choice alternatives which included the opportunity of choosing from between the car mode with various parking options, the bus and the bicycle. It was decided not to include the on-foot mode because of the quite long distances between the two recreational zones:

- ALTERNATIVE 1: Travel by car and park at a paid car park in the area close to the beach (the most popular destination during the holiday season).

- ALTERNATIVE 2: Travel by car and park in a designated area along a public road at an hourly rate.

- ALTERNATIVE 3: Travel by car and park at a park and ride car park connected by a shuttle bus to the beach area and village centre.

- $\quad$ ALTERNATIVE 4: Travel by the local public bus service.

- ALTERNATIVE 5: Travel by public hired bicycle.

It needs to be pointed out that these last two alternatives are only available for those people whose journey origin and destination are within the local area, as these services could not be used if that were not the case.

The experiment designed for the alternatives presented above included the following choice variables:

- Cost of off-street parking [FEE PPP $_{\text {- }}$ in $€$ per day.

- Cost of on-street parking [FEE $\left.\mathrm{FESP}_{\mathrm{P}}\right]$ in in $€$ per hour.

- Bus fare $\left[\mathrm{FEE}_{\mathrm{Bus}}\right]$ in $€$.

- Access time from parking spot to beach [AT] in minutes.

- Waiting time at the stop [WT] in minutes.

- $\quad$ Travel time [TT] in minutes.

- Cruise for parking time [SPT] in minutes.

A series of variables defined each of these alternatives and helped the potential users to understand the different situations they were being presented with. Both the variables and their ranges depended on each alternative, all of which are summarised below in Table 1.

As can be seen in Table 1, as available on-street parking spaces are near to the beach, the required access time (AT) for alternative 2 was low in all cases. The same happened with bus stops, which can be placed in the roads adjacent to the beaches, which minimized its value. Regarding waiting time values 
(WT), they were different for the bus shuttle (Alternative 3) and for the regular public transport service (alternative 4), which were higher. The main reason is that the regular transport service has been more focused on residents for different trip purposes. However, the authors wanted to study the willingness to use this service as a complementary service for beach trips purpose. The cruise for parking time (SPT) values were chosen according to a revealed preference carried out to evaluate the current situation of the town. These times varied depending on how far they were from the beach. The more distance to the beach, the less occupation rate, and, therefore, the more probability of finding an empty parking space.

Table 1. Summary of the variables used for each alternative (Alt.) with their variation ranges.

\begin{tabular}{|c|c|c|c|c|c|}
\hline & Alt. 1 & Alt. 2 & Alt. 3 & Alt.4 & Alt. 5 \\
\hline $\mathrm{FEE}_{\mathrm{PPP}}(€ /$ day $)$ & $\begin{array}{l}4 \\
6 \\
8\end{array}$ & & & & \\
\hline FEE $_{\text {POSP }}(€ / h)$ & & $\begin{array}{c}0.6 \\
1 \\
1.5\end{array}$ & & & \\
\hline $\mathrm{FEE}_{\mathrm{BUS}}(€)$ & & & $\begin{array}{l}1 \\
2 \\
3\end{array}$ & $\begin{array}{c}0.6 \\
1 \\
1.3\end{array}$ & \\
\hline AT (min) & $\begin{array}{l}2 \\
5 \\
8\end{array}$ & $\begin{array}{l}2 \\
5 \\
8\end{array}$ & & & \\
\hline WT (min) & & & $\begin{array}{c}5 \\
8 \\
10\end{array}$ & $\begin{array}{c}5 \\
10 \\
20\end{array}$ & \\
\hline TT (min) & & & $\begin{array}{l}4 \\
6 \\
8\end{array}$ & $\begin{array}{c}6 \\
10 \\
15\end{array}$ & $\begin{array}{c}8 \\
14 \\
20\end{array}$ \\
\hline SPT (min) & & $\begin{array}{l}2 \\
5 \\
8\end{array}$ & & & \\
\hline
\end{tabular}

Efficient design based on D-error measurements was used to create the optimal design for the survey scenarios. This method of working not only minimised correlation between attributes, its aim was to estimate parameters with the minimum possible standard error [26].

Therefore, the final SP survey consisted of six choice scenarios by varying the value of the attributes of Table 1 of the five alternatives explained before. The combination of variables for each alternative at each scenario can be seen in Table 2.

Table 2. Final scenarios of the stated preference survey.

\begin{tabular}{|c|c|c|c|c|c|c|c|}
\hline Alternative & Variable & ESC. 1 & ESC. 2 & ESC. 3 & ESC.4 & ESC. 5 & ESC. 6 \\
\hline \multirow{2}{*}{ Alt. 1: Car + beach parking } & $\begin{array}{l}\text { FEE } \\
\text { (€/day) }\end{array}$ & 4 & 6 & 8 & 8 & 4 & 6 \\
\hline & $\mathrm{AT}(\mathrm{min})$ & 8 & 2 & 5 & 2 & 8 & 5 \\
\hline \multirow{3}{*}{ Alt. 2: Car + on-street parking } & $\operatorname{FEE}_{\text {POSP }}(€ / h)$ & 0.6 & 1 & 1.5 & 0.6 & 1 & 1.5 \\
\hline & $\mathrm{ST}(\mathrm{min})$ & 8 & 2 & 5 & 8 & 2 & 5 \\
\hline & AT (min) & 5 & 8 & 2 & 5 & 8 & 2 \\
\hline \multirow{3}{*}{ Alt. 3: Park\&Ride } & $\mathrm{FEE}_{\mathrm{BUS}}(€)$ & 3 & 2 & 2 & 1 & 1 & 3 \\
\hline & WT (min) & 8 & 10 & 10 & 5 & 8 & 5 \\
\hline & $\mathrm{TT}$ (min) & 6 & 6 & 6 & 8 & 8 & 8 \\
\hline \multirow{3}{*}{ Alt. 4: Public bus service } & $\operatorname{FEE}_{\mathrm{BUS}}(€)$ & 0.6 & 1.3 & 1 & 1 & 0.6 & 1.3 \\
\hline & $\mathrm{WT}(\mathrm{min})$ & 5 & 5 & 10 & 20 & 20 & 10 \\
\hline & $\mathrm{TT}(\mathrm{min})$ & 15 & 6 & 15 & 10 & 6 & 10 \\
\hline Alt. 5: Public bike sharing system & TT (min) & 20 & 14 & 8 & 14 & 20 & 8 \\
\hline
\end{tabular}


Once the six scenarios were designed, the pilot survey was developed not only to corroborate the goodness of fit, but also to serve as the basis for the efficient design (D-error) and the estimation of the sample size for the final survey using the following expression proposed by Rose and Bliemer [26].

$$
N>\left(\frac{1.96 s e\left(\beta_{k}\right)}{\beta_{k}}\right)^{2}
$$

where $N$ is the sample size, $\beta_{k}$ is the estimator of the critical parameter, $\operatorname{se}\left(\beta_{k}\right)$ its standard error and 1.96 the value of the standard normal variable at a $95 \%$ confidence level. The result of this exercise was that a sample size of over 600 valid observations should provide parameters significant at the $95 \%$ level. Figure 3 provides an example of the survey form used.

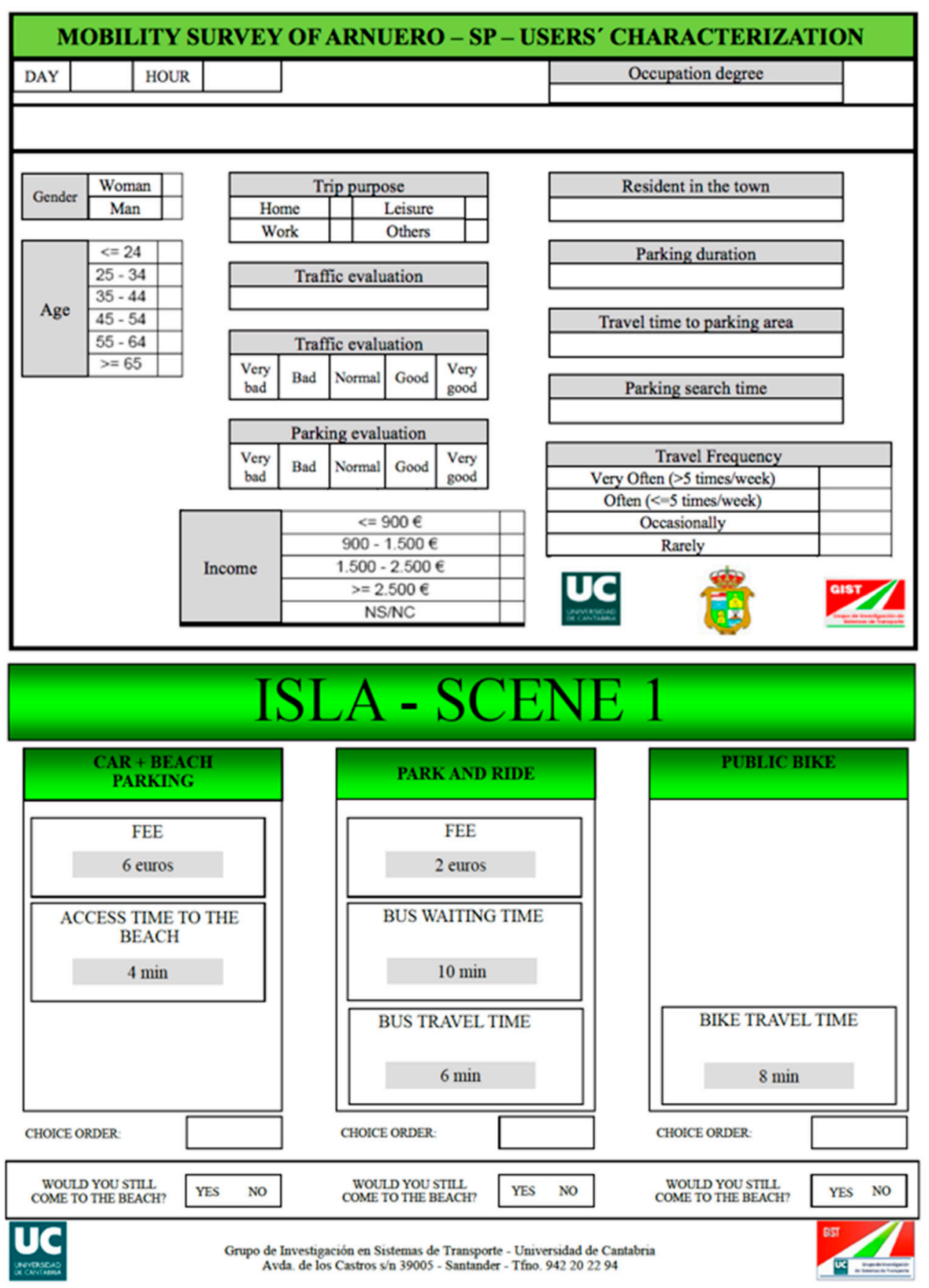

Figure 3. Screenshot of the survey form. 


\section{Discrete Choice Model Estimation and Findings on Parking Choice}

The discrete choice models estimated in this research have been presented below. This particular research estimated mixed logit models due to their versatility, or rather, their capacity to work whilst considering randomness in the taste of the potential users [27,28].

Mixed logit models were estimated for the different parking alternatives described beforehand and an individual utility function was calculated for each one. These utility functions have considered the variables indicated in the stated preferences experiment as well as other specific socioeconomic variables for the study area. As a result, the following variables were found to be significant in the estimation of the discrete choice models:

- FEE: Parking fee (specific parameters for paid private parking (FEE (FEE $\left.E_{\mathrm{POSP}}\right)$ ) or bus fare (specific parameters for the regular bus service ( $\mathrm{FEE}_{\mathrm{BUS}}$ ) and the $\mathrm{P}$ and $\mathrm{R}$ service (FEE $E_{B U S(P \& R))}$ ).

- $\quad$ TT: Travel time (specific parameter for the regular bus service $\left(\mathrm{TT}_{\mathrm{BUS}}\right)$ and the $\mathrm{P}$ and $\mathrm{R}$ service $\left(\mathrm{TT}_{\mathrm{P \& R}}\right)$ ).

- WT: Waiting time (specific for the regular bus service ( $\mathrm{WT}_{\mathrm{BUS}}$ ) and bus shuttle of the $\mathrm{P}$ and $\mathrm{R}$ service $\left.\left(\mathrm{WT}_{\mathrm{P} \& \mathrm{R}}\right)\right)$.

- $\quad$ AT: Access time (generic parameter for the option of paid parking).

- $\mathrm{FEE}_{\mathrm{PPP}}$ (AGE<24 YEARS): Interaction of the socioeconomic variable age under 24 years old and private parking fee.

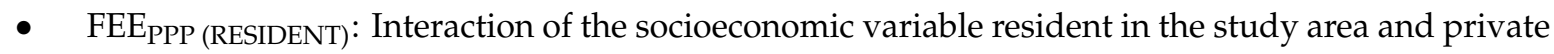
parking fee.

- FEE $\mathrm{FOSP}$ (INCOME. $>2500 € /$ month): Interaction of the socioeconomic variable income level greater than 2500 euros/month and paid on-street parking fee.

- FEE on-street parking fee.

- $T_{\text {P\&R(RESIDENT) }}$ : Interaction of the socioeconomic variable resident in the study area and travel time by regular bus or $P \& R$.

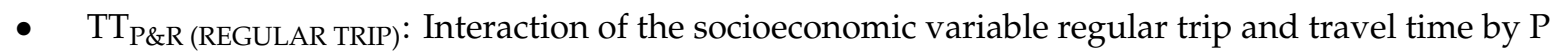
and $R$ bus.

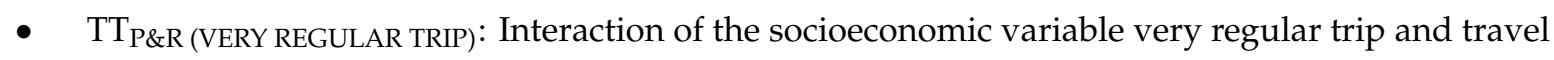
time by $P$ and $R$ bus.

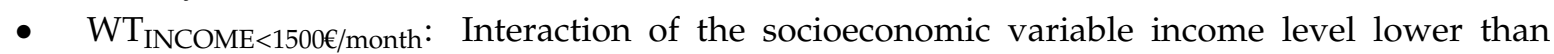
1500 euros/month and waiting time for regular bus service.

- $\mathrm{AT}_{(\mathrm{RESIDENT})}$ : Interaction of the socioeconomic variable resident in the study area with access time to bus.

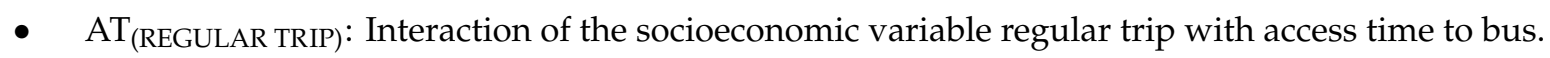

Table 3 shows the results of the mixed logit model estimated with the variables presented above. 
Table 3. Coefficients and statistical test for the discrete choice models.

\begin{tabular}{|c|c|c|c|}
\hline Variable & Coefficient & $t$ Test & $\mathrm{P}[|Z|>z]$ \\
\hline \multicolumn{4}{|c|}{ Random parameters in utility functions } \\
\hline $\mathrm{FEE}_{\mathrm{PPP}}$ & -0.795 & -8.684 & 0.000 \\
\hline FEE & -3.941 & -4.953 & 0.000 \\
\hline $\mathrm{TT}_{\mathrm{P} \& \mathrm{R}}$ & -0.544 & -4.673 & 0.000 \\
\hline $\mathrm{WT}_{\mathrm{P} \& \mathrm{R}}$ & -0.546 & -3.565 & 0.000 \\
\hline AT & -0.406 & -7.443 & 0.000 \\
\hline \multicolumn{4}{|c|}{ Nonrandom parameters in utility functions } \\
\hline $\mathrm{FEE}_{\mathrm{BUS}(\mathrm{P} \& \mathrm{R})}$ & -1.083 & -4.808 & 0.000 \\
\hline FEE $_{\text {BUS }}$ & -5.927 & -4.695 & 0.000 \\
\hline $\mathrm{TT}_{\mathrm{BUS}}$ & -0.355 & -3.074 & 0.002 \\
\hline $\mathrm{WT}_{\mathrm{BUS}}$ & -0.192 & -2.576 & 0.010 \\
\hline \multicolumn{4}{|c|}{ Heterogeneity in mean Parameter } \\
\hline FEE $_{\text {PPP(AGE<24 YEARS) }}$ & -0.174 & -1.344 & 0.179 \\
\hline $\mathrm{FEE}_{\mathrm{PPP}(\mathrm{RESIDENT})}$ & -2.043 & -4.480 & 0.000 \\
\hline FEEPOSP(INCOME.>2500€/month) & 1.206 & 1.58 & 0.114 \\
\hline FEE & -5.634 & -3.136 & 0.002 \\
\hline $\mathrm{TT}_{\mathrm{P} \& \mathrm{R}(\mathrm{RESIDENT})}$ & -0.827 & -2.476 & 0.013 \\
\hline $\mathrm{TT}_{\mathrm{P} \& \mathrm{R} \text { (REGULAR TRIP) }}$ & -0.338 & -2.423 & 0.015 \\
\hline $\mathrm{TT}_{\text {P\&R (VERY REGULAR TRIP) }}$ & -0.498 & -2.391 & 0.017 \\
\hline $\mathrm{WT}_{\mathrm{INCOME}<1500 € / \text { month }}$ & -0.347 & -2.360 & 0.018 \\
\hline $\mathrm{AT}_{(\mathrm{RESIDENT})}$ & -0.642 & -1.837 & 0.066 \\
\hline AT (REGULAR TRIP) & -0.268 & -2.667 & 0.008 \\
\hline \multicolumn{4}{|c|}{ Derived standard deviations of parameter distributions } \\
\hline $\mathrm{N}\left(\mathrm{FEE}_{\mathrm{PPP}}\right)$ & 0.354 & 6.016 & 0 \\
\hline $\mathrm{N}\left(\mathrm{FEE}_{\mathrm{POSP}}\right)$ & 1.463 & 2.973 & 0.003 \\
\hline $\mathrm{N}\left(\mathrm{TT}_{\mathrm{P} \& \mathrm{R}}\right)$ & 0.240 & 2.871 & 0.004 \\
\hline $\mathrm{N}\left(\mathrm{WT}_{\mathrm{P} \& \mathrm{R}}\right)$ & 0.457 & 4.888 & 0 \\
\hline $\mathrm{N}(\mathrm{AT})$ & 0.195 & 2.156 & 0.031 \\
\hline \multicolumn{2}{|l|}{ Log-Likelihood } & \multicolumn{2}{|c|}{-576.727} \\
\hline \multicolumn{2}{|c|}{ Log-Likelihood (Constants only) } & \multicolumn{2}{|c|}{-1376.039} \\
\hline
\end{tabular}

As can be seen in Table 3, various variables have been found to show randomness in the estimation of their associated parameters. The variables which showed evidence of randomness in the parameters were as follows:

For alternative 1, travel by car and park in a paid car park:

- $\quad$ Parking fee of private parking (FEE $\mathrm{PPP})$.

For alternative 2, travel by car and park along the public road at an hourly rate:

- $\quad$ Parking fee of street parking (FEE FOSP $)$ )

- Access time (AT) from the parking space to the real trip destination (beach or leisure zone).

For alternative 3, travel by car and use the P\&R car park with shuttle bus service:

- $\quad$ Trip time in the P and R shuttle bus ( $\left.\mathrm{TT}_{\mathrm{P} \& \mathrm{R}}\right)$.

- Waiting time for the $\mathrm{P}$ and $\mathrm{R}$ shuttle bus ( $\left.\mathrm{WT}_{\mathrm{P} \& \mathrm{R}}\right)$.

In the case of alternatives 4 and 5 , no evidence of randomness was found in the significant variables obtained in the estimation of discrete choice models. This finding showed that randomness occurred in the alternatives that were related to private vehicles and were available to both residents and 
non-residents. Therefore, considering private vehicle alternatives available to all the users, regardless of their place of origin, the heterogeneity of the preferences increased.

The function that best represents the random behaviour in the tastes associated with these variables has been, in all cases, the normal function. The rest of the variables have been associated with fixed parameters, in other words, the potential users who perceive in the same way.

Nevertheless, there are various interactions of the variables that resulted randomly with socioeconomic variables which have tried to explain the randomness in the perception of these variables.

The age of the potential users is influential in the case of the parking fee, as well as the users' residency or not in the borough. The younger users and the residents have been more affected by the fact they have to pay to park in those car parks. Similarly, the hourly fee associated with parking along the public road was seen to be affected by the income levels of the potential users-as income levels increase, this variable becomes less important. However, the fact that they are residents in the area affects them even more so, and they place much more importance on this variable than the rest of the potential users.

Another variable seen to be affected by certain characteristics of the potential users is the travel time of the $P$ and $R$ shuttle bus. The weights of the parameters associated with this variable depend on whether or not the user is a local resident and the frequency of the journey being made. As happened with the other variables, the residents penalise this variable more than the other potential users do. As journey frequency increases, the weight placed by the potential users on this variable falls. In other words, those people who use the service on a daily basis place less importance on the journey time than those that use the service weekly. Those that use the service on a weekly basis penalise it less that those people using the service on an ad hoc basis, every now and again.

This analysis showed that once the potential users considered the destination to be the priority (being regular or very regular), they were more aware of the benefits associated with the $\mathrm{P}$ and $\mathrm{R}$ car park and its shuttle bus, considering the associated travel time as something that can be easily tolerated. When the destination was circumstantial, or ad hoc, the fact that they depended on the shuttle bus to reach their final destination was an important handicap that the users considered.

\section{Simulation and Policies}

In order to analyse user behaviour when faced with the various different policies that could be introduced, the authors modelled different combinations of fees for the car parks, shuttle service and other transport services and obtained the expected percentage distribution in the choices made by the users. The following tables showed the choices made by the users for each simulated scenario.

Three possible policies have been simulated depending on the fees to be charged for each of the services being studied.

Table 4 showed the distribution resulting from the discrete choice model simulating the introduction of this policy. In the case of constructing a private car park with a daily fee of 3 euros, the user behaviour showed that in all the studied cases, that car park would capture more than a $50 \%$ share.

Table 4. Policy simulation 1 (\% share).

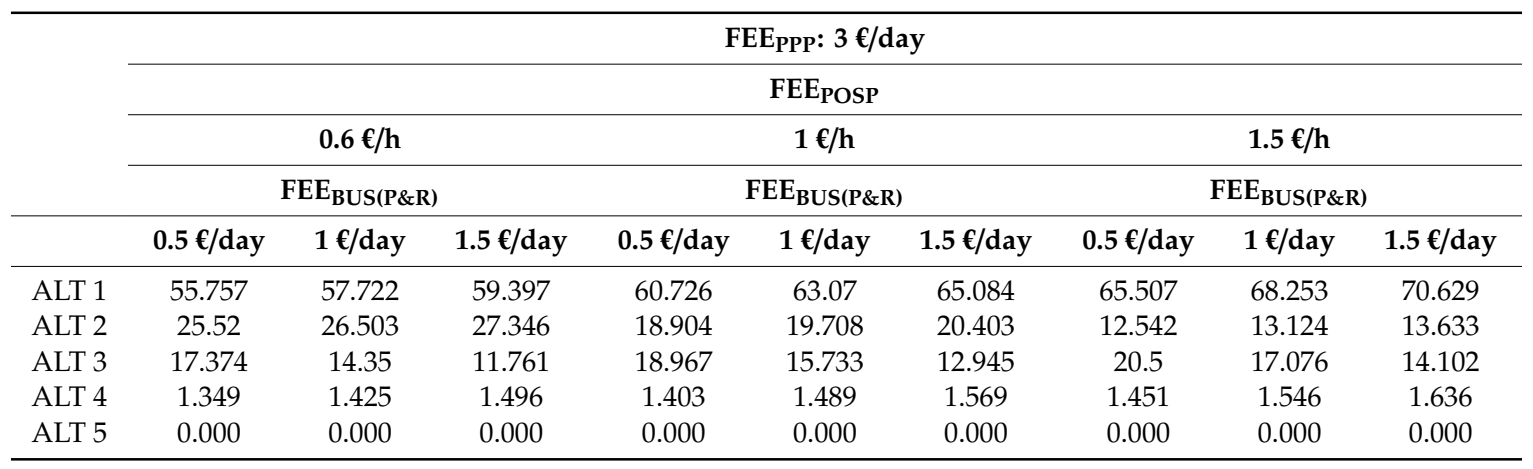


As with Table 4, Table 5 represented the second possible parking management policy and in this case, it can be seen how a $1 €$ increase in the private parking fee resulted in a greater than $10 \%$ reduction in this alternative being chosen rather than the other alternatives. This scenario showed how the alternatives that increased their share are the other two parking choices, on street and P and R, with street parking showing the bigger increase.

Table 5. Policy simulation 2 (\% share).

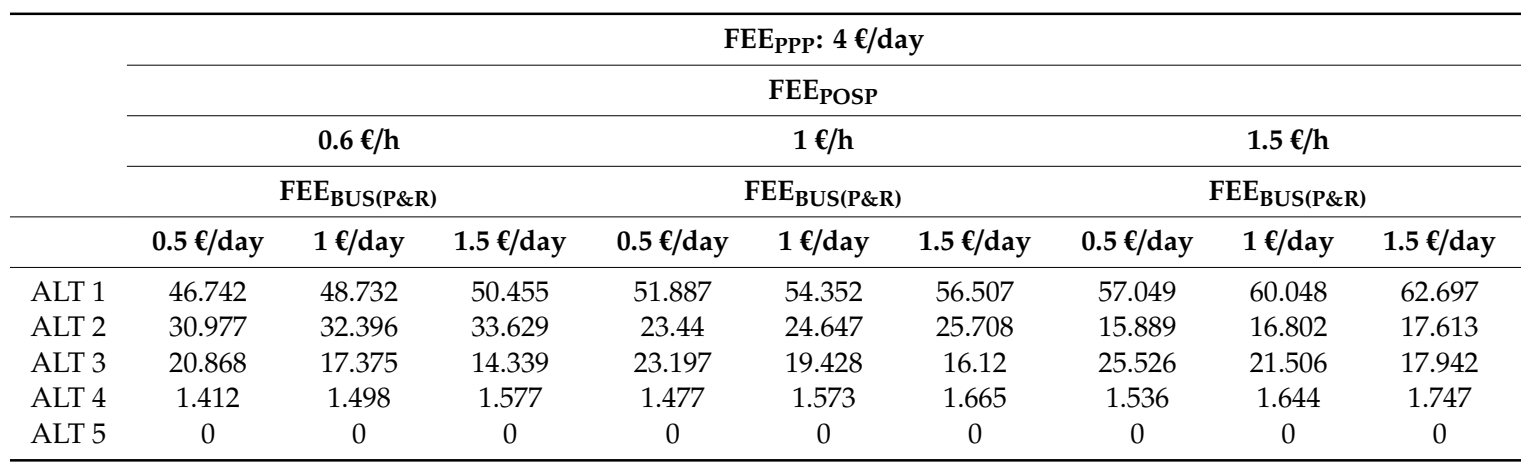

Finally, the third possible parking policy was simulated and, as with policy 2, the private parking fee was increased, this time by introducing a tariff of $5 € /$ day. Table 6 showed a similar result to the previous case with a reduction of approximately $10 \%$ in the choice of private parking. This $10 \%$ was shared between alternatives 2 and 3 and in this particular case, the shares of alternatives 1 and 2 were very similar.

Table 6. Policy simulation 3 (\% share).

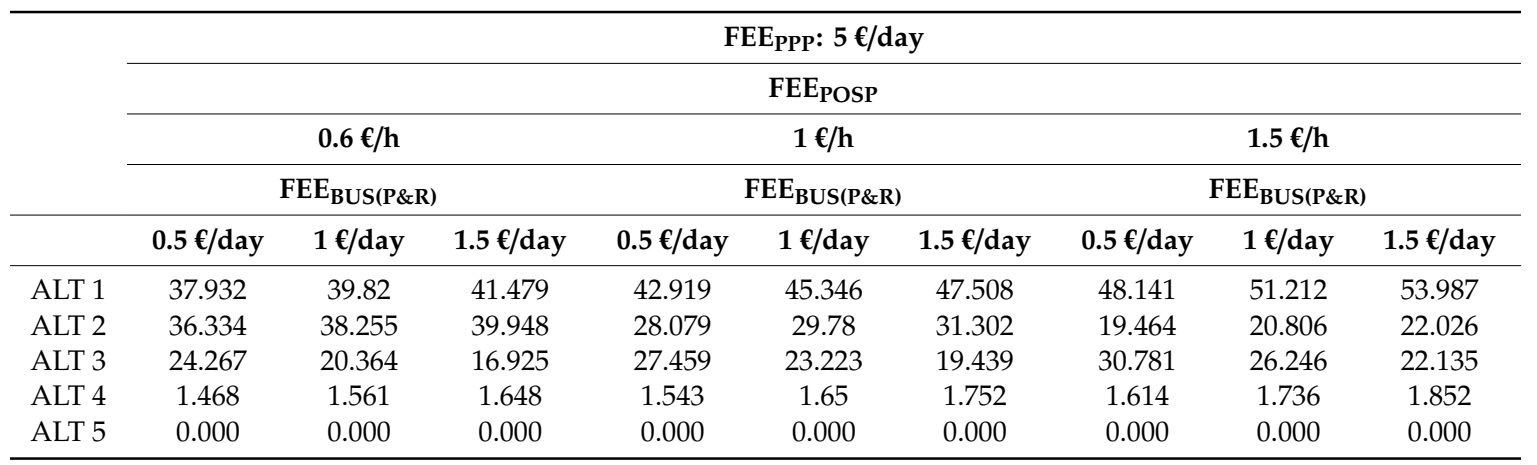

As observed beforehand, private parking was the most popular choice in all cases and the P and R choice never surpassed $30 \%$ in any of the cases studied, even with the more unfavourable parking fees.

Based on the results obtained from the modelling and the scenarios, the following policies were introduced:

- $\quad$ Fee charging for the large urban and beach parking areas.

- Limitations imposed on urban street parking.

- $\quad$ Two P and R car parks with 450 spaces and shuttle buses every $15 \mathrm{~min}$ for a seven minute journey with no stops along the way.

An analysis was performed on the chosen policy to estimate the expected income generated and the running costs of the system which can be seen in Table 7. It is important to highlight that the car parks and shuttle buses are only operational during the summer months. The personnel cost referred in Table 7 focused solely on the collection fare personnel of paid parking in the town center and on the beach (not the P and R). The cost has been estimated assuming $8 \mathrm{~h}$ of operation (from 11:30 to 
19:30) for three months (from 15 June to 15 September) with the minimum wage in Spain (approx. $1400 €$ gross/month), being necessary for six people. In the case of the shuttle buses, they only run at weekends and on public holidays by using two vehicles (minibuses) every $15 \mathrm{~min}, 3.7 \mathrm{~km}$ average cycle length, operating only on weekends in July and August, seven hours per day), while the local public transport service is operational all year round, with $1 \mathrm{~h}$ headway, by using a single vehicle $10 \mathrm{~h} /$ day for 250 days. Furthermore, the operating cost is based on the following unit costs-personnel cost: $16 € / \mathrm{h}$, running cost: $0.66 € / \mathrm{km}$.

Table 7. The calculation of income and costs of the proposed measures (first year).

\begin{tabular}{ccccc}
\hline & Parking/Shuttle Buses & Municipal Transport & Personnel & Total \\
\hline Income & $86,486.50 €$ & $7,261.85 €$ & & $93,748.36 €$ \\
\hline Costs & $11,441.73 €$ & $69,309.03 €$ & $25,967.74 €$ & $106,718.50 €$ \\
\hline Balance & $75,044.77 €$ & $-62,047.18 €$ & $-25,967.74 €$ & $-12,970.65 €$ \\
\hline
\end{tabular}

The results showed that with a subsidy of approximately $13,000 €$ per year, the local residents would benefit from the use of a new municipal transport service. According to the household survey carried out, the municipality has a large percentage of elderly people without a car, whose daily journeys will be covered by this new service. It is also worth noting that our calculations have not considered income generated by advertising revenue from bus stops, vehicles, etc. which would also contribute towards reducing the cost of the service to the public purse and could potentially pay for the system completely or even generate profits.

\section{Conclusions}

The main goal of this work was to present the application of a methodology designed to manage existing parking systems and the possible measures that could be introduced along with other modes of transport in coastal areas where there is a concentrated demand for access during holiday seasons.

The results of the survey showed that only the actual residents surveyed in the study area would like to see the introduction of a regular bus service. In the case of a public bicycle service, neither the survey nor the estimated models found any relevant results in favour of its use. These results were expected due the low service frequency and the difficulties that cycling offers to the users when travelling to the beach to carry all their items.

The most relevant factors influencing the users' choices have been the parking fee and distances to the beach for all parking based alternatives; and travel time of the bus shuttle and waiting time for the alternative based on $P$ and $R$.

The results from the models indicated how the tariffs chosen for the designed paid parking alternatives showed important significance on the model specification and provided clear evidence of randomness which, as indicated previously, denoted the variety in the perception of said variable. The results showed that the randomness of the private parking fee was explained by residence in the study area and being under 24 years old and by incomes higher than $2500 €$. Regarding the time related variables, the randomness evidence was explained by residences in the study area, trip frequency, and income under $1500 €$.

Once the models were estimated, the simulations were able to provide the orders of magnitude of the fees and the different times required should the studied policies be introduced. The three simulated policies showed that neither alternative 4 (regular bus service) nor alternative 5 (travelling by bicycle) obtained representative results, as in all cases the users overwhelmingly chose the alternatives that involved car parking (alternatives 1,2 and 3). This is because the main reason the survey interviewees were travelling was for leisure purposes and they were travelling from other urban settlements to go to the beaches. This kind of user, making an infrequent journey, is more likely to travel using their own car than to use public transport. For alternatives 1,2 and 3, and based on the simulations 
made, parking was found to affect the users choices more than the service attributes of the bus shuttle, if headways were under $15 \mathrm{~min}$, for the case study considered, especially in the case of regular and non-regular trips.

The estimated models allowed the authors to study the modal choice distribution, considering parking, resulting from the introduction of the different parking and mobility management policies. This analysis has shown that, in spite of the current strong dependence on the car among the users travelling to the study area, relative low parking fees and on-street parking regulation, complemented with a well-designed $\mathrm{P}$ and $\mathrm{R}$ facilities can reduce up to $25 \%$ of the traffic inflow (and therefore reducing all the congestion externalities and the parking space needs) and generate enough incomes to compensate for the operation costs of not only their own system, but also a regular public transport service that benefits the residents life.

Author Contributions: Conceptualization, L.d. and G.A.; methodology, G.A.; software, G.A. and B.A.; validation, B.A. and R.C., data curation, B.A.; writing-original draft preparation, G.A., B.A. and R.C.; writing-review and editing, R.C. and B.A.; supervision, L.d.

Funding: This study and the development of future research are possible thanks to financing from the Spanish Ministerio de Economía, Industria y Competitividad from the projects referenced TRA2013-48116-R and TRA2017-85853-C2-1-R.

Acknowledgments: The authors would like to show their gratitude to Angel Ibeas of the University of Cantabria for his support during this research.

Conflicts of Interest: The authors declare no conflicts of interest.

\section{References}

1. Hillery, M.; Nancarrow, B.; Griffin, G.; Syme, G. Tourist perception of environmental impact. Ann. Tour. Res. 2001, 28, 853-867. [CrossRef]

2. Khamung, R. Mature Coastal Destinations and Management Strategy for the ASEAN Regional Integration of Sustainable Coastal Tourism. ASEAN J. Manag. Innov. 2018, 5, 113-127.

3. Management of Coastal Recreational Resources Beaches, Yacht Marinas and Coastal Ecotourism. Available online: https://www.um.edu.mt/ies/publications/mcrr1proceedings (accessed on 26 June 2019).

4. Phillips, M.R.; House, C. An evaluation of priorities for beach tourism: Case studies from South Wales, UK. Tour. Manag. 2009, 30, 176-183. [CrossRef]

5. Lumsdon, L.; Page, S.J. Tourism and Transport: Issues and Agenda for the New Millennium; Elsevier Science Ltd.: Amsterdam, The Netherlands, 2004.

6. Prideaux, B. The role of the transport system in destination development. Tour. Manag. 2000, $21,53-63$. [CrossRef]

7. Gutiérrez, A.; Miravet, D. The determinants of tourist use of public transport at the destination. Sustainability 2016, 8, 908. [CrossRef]

8. Mandeno, T.G. Is Tourism a Driver for Public Transport Investment? Master's Thesis, University of Otago, Dunedin, New Zealand, 2011.

9. Petrosillo, I.; Zurlini, G.; Corlian, M.E.; Zaccarelli, N.; Dadamoa, M. Tourist perception of recreational environment and management in a marine protected area. Landsc. Urban Plan. 2007, 79, 29-37. [CrossRef]

10. Pendleton, L.; Martin, N.; Webster, D.G. Public perception of environmental quality: A survey study of beach use and perceptions in Los Angeles County. Mar. Pollut. Bull. 2001, 42, 1155-1160. [CrossRef]

11. Gössling, S. Carbon Management in Tourism: Mitigating the Impacts on Climate Change; Routledge: London, UK, 2010.

12. Phillips, M.R.; Jones, A.L. Erosion and tourism infrastructure in the coastal zone: Problems, consequences and management. Tour. Manag. 2006, 27, 517-524. [CrossRef]

13. Bramwell, B.; Lane, B. Priorities in sustainable tourism research. [Editorial]. J. Sust. Tour. 2008, 16, 1-4. [CrossRef]

14. Snousy, M.G.; Zawrah, M.F.; Abdel-Moghny, T.; Ebiad, M.A.; Rashad, A.M.; Khalil, M.M.; Tantawy, M.A. Mobility and Fate of Pollutants in the Aquifer System of the Northwestern Suez Gulf, Egypt. Rev. Env. Contam. Toxicol. 2017, 240, 169-195. 
15. Nurul Habib, K.M.; Morency, C.; Trépanier, M. Integrating parking behavior in activity-based travel demand modelling: Investigation of the relationship between parking type choice and activity scheduling process. Transp. Res. A-Pol. 2012, 46, 154-166.

16. Chaniotakis, E.; Pel, A.J. Drivers' parking location choice under uncertain parking availability and search times: A stated preference experiment. Transp. Res. A-Pol. 2015, 82, 228-239. [CrossRef]

17. Ibeas, A.; dell'Olio, L.; Bordagaray, M.; Ortúzar, J.D. Modelling parking choices considering user heterogeneity. Transp. Res. A-Pol. 2014, 70, 41-49.

18. Steiner, T.J.; Bristow, A.L. Road pricing in National Parks: A case study in the Yorkshire Dales National Park. Transp. Policy 2000, 7, 93-103. [CrossRef]

19. Coleman, C.; Curtis, C. Reducing car-based journeys to work: What potential is there and whose responsibility is it? Local Environ. 1999, 4, 23-38. [CrossRef]

20. Regnerus, H.D.; Beunen, R.; Jaarsma, C.F. Recreational traffic management: The relations between research and implementation. Transp. Policy 2007, 14, 258-267. [CrossRef]

21. Holding, D.M. The Sanfte Mobilitaet project: Achieving reduced car-dependence in European resort areas. Tour. Manag. 2001, 22, 411-417. [CrossRef]

22. Holding, D.M.; Kreutner, M. Achieving a balance between 'carrots' and 'sticks' for traffic in National Parks: The Bayerischer Wald project. Transp. Policy 1998, 5, 175-183. [CrossRef]

23. Van der Waerden, P.; Borgers, A.; Timmermans, H. Consumer response to the Introduction of paid parking in a regional shopping center. Transp. Res. Record 2009, 2118, 16-23. [CrossRef]

24. Dixon, A.W.; Oh, C.O.; Draper, J. Access to the beach: Comparing the economic values of coastal residents and tourists. J. Travel Res. 2012, 51, 742-753. [CrossRef]

25. Downward, P.; Lumsdon, L. Tourism Transport and Visitor Spending: A Study in the North York Moors National Park, UK. J. Travel Res. 2004, 42, 415. [CrossRef]

26. Rose, J.M.; Bliemer, M.C.J. Constructing efficient stated choice experimental designs. Transp. Rev. 2009, 29, 587-617. [CrossRef]

27. Ortúzar, J.D.; Willumsen, L.G. Modelling Transport; John Wiley and Sons: Chichester, UK, 2001.

28. Train, K.E. Discrete Choice Methods with Simulation; Cambridge University Press: Cambridge, UK, 2009.

(C) 2019 by the authors. Licensee MDPI, Basel, Switzerland. This article is an open access article distributed under the terms and conditions of the Creative Commons Attribution (CC BY) license (http://creativecommons.org/licenses/by/4.0/). 